\title{
Una actualización de la Disputa de Valladolid, o acerca de cómo se ingresa en la comunidad de comunicación
}

\author{
Federica Scherbosky' \\ https://orcid.org/0000-0002-0601-8979 \\ I - Facultad de Educación de la UNCuyo \\ Mendoza, Argentina
}

Resumen: La Disputa de la Valladolid, llevada a cabo entre 1550 y 1551, buscaba resolver los parámetros de humanidad de los pueblos originarios, en función de su consecuente evangelización. ¿Tenían alma los indígenas? ¿Podían entonces evangelizarse? ¿De qué modo? Fueron los interrogantes de los pensadores de la época. Nos interesa, sin embargo, poner en consideración la lectura de la Disputa que realiza el filósofo Enrique Dussel, en torno a dos cuestiones que consideramos relevantes. Una es la vinculación con la comunidad de comunicación que plantea el filósofo alemán Karl Otto Apel y otra es su denuncia de lo que denomina el mito de la modernidad y su correspondiente crítica. Pretendemos pensar cómo el análisis que hace Dussel, cobra mayor vigencia día a día ¿Quiénes son considerados humanos hoy? ¿Con quiénes podemos dialogar? ¿Quiénes consideramos que tienen algo valioso para decirnos? Son algunas de las preguntas que guían este trabajo.

Palabras clave: comunidad de comunicación; mito de la modernidad; filosofía de la liberación; alteridad.

Abstract: An update of the Valladolid Debate, or how to join the communication community The Valladolid Debate (1550-1551), sought to establish human parameters regarding the indigenous peoples of the Americas in order to justify their conversion to Catholicism. Did the Indians possess a soul? Could they be converted to Christianity? How? Such were the questions of the scholars of that time. But we are interested in the philosopher Enrique Dussel's reading of the Debate, especially concerning two questions we consider relevant. One is the connection with the "communication community" as posed by the German philosopher Karl Otto Apel, and the other is Dussel's exposure of what he calls the "myth of modernity" and its corresponding critique. We see Dussel's analysis become more effective day by day. Who are considered humans today? With whom can we dialogue? Who do we consider having something valuable to tell us? These are some of the questions that guide this work.

Keywords: communication community; myth of modernity; philosophy of liberation; otherness. 


\section{La Disputa de Valladolid: contexto y tesis principales.}

Enrique Dussel, filósofo mendocino nacido en 1934, retoma la Disputa de Valladolid en su libro, 1492 el encubrimiento del otro. Hacia el origen del "Mito de la modernidad". (1994), particularmente en la Conferencia 5 denominada Crítica del "mito de la Modernidad". Esta Disputa fue un debate que tuvo lugar en 1550 y 1551 en el Colegio de San Gregorio de Valladolid, dentro de la Polémica de los naturales, refiriéndose a los indígenas americanos o indios, como se les Ilamaba en la época. Esta enfrentó das formas antagónicas de concebir la Conquista de América; aunque fueron más las perspectivas participantes, de hecho Dussel retoma tres de ellas. Normalmente, se plantean dos: la de los defensores y la de los enemigos de los pueblos originarios. La primera estuvo representada por Bartolomé de las Casas (1474-1566), considerado hoy, pionero de la lucha por los derechos; y la segunda, por Juan Ginés de Sepúlveda (1490-1573), que defendía el derecho y la conveniencia del dominio de los españoles sobre los pueblos originarios, a quienes concebía como naturalmente inferiores. Dussel retoma también la postura, más bien utópica, de Gerónimo de Mendieta (1525-1604), quien pretendía crear una República Indiana en América. Los estudios y reflexiones públicas efectuadas para esta Junta fueron excepcionales, en comparación con cualquier otro proceso de conquista. Cabe destacar la gran importancia del des/encubrimiento ${ }^{1}$ de América para la Monarquía Española y la necesidad de perpetuar el control de ese extenso territorio, cuestión que les habilitó un enriquecimiento desmedido y la posibilidad de erigirse como primer país moderno, junto con Portugal (Dussel, 2000).

El precedente de la Junta de Valladolid fue la Junta de Burgos de 1512, que había avalado jurídicamente el derecho a hacer la guerra a los indios que se resistieran a la evangelización. Se buscó un equilibrio entre el predominio social de los colonizadores y la protección al indio, que pretendió conseguirse con la encomienda. Aunque sabemos que las condiciones de esta, lejos estaba de implicar una vida digna para los pueblos colonizados, pues solo mejoraron las condiciones para que estos conservaran su vida y siguieran siendo utilizados como mano de obra gratuita. En el caso de la población negra las condiciones fueron radicalmente peores, de hecho no entraron en consideración en la Disputa, pues estaban dentro del mercado esclavista.

Aunque es la versión más corriente, la Disputa no discurrió, o al menos oficialmente, en torno a si los indios eran seres humanos con alma o simples salvajes que podían ser domesticados como animales, sino a los derechos naturales de los habitantes del Nuevo Mundo, las justas causas para hacerles la guerra y la legitimidad de la Conquista. Francisco de Vittoria fue central en estas discusiones, y aunque ya había fallecido para la Disputa, su pensamiento acerca de la injusticia de la Conquista impregnó el debate. ${ }^{2}$

1 Dussel critica la noción de "descubrimiento" de América y prefiere hablar de un "encubrimiento del otro", instancias que desarrollaremos más adelante en el artículo.

2 Cfr. La tesis doctoral de OSORIO, 2019. 
El propósito declarado de la Junta de Valladolid era ofrecer una base teológica y de derecho para decidir cómo debía procederse en los descubrimientos, conquistas y con la población de las Ilamadas Indias. Sepúlveda publicó su De la justa causa de la guerra contra los indios (c 1550) y Las Casas replicó con sus Treinta proposiciones muy jurídicas (c 1550). Sepúlveda aportó un trabajo titulado Democrates alter, en el que sostenía que los indios, considerados como seres inferiores, debían quedar sometidos a los españoles, y lo completó con más argumentaciones en el mismo sentido. La Apologética Historia Sunaria (1536) de Las Casas fue el texto clave en las discusiones. La Junta quedó inconclusa y por ello volvió a convocarse el año siguiente. En la disputa no hubo resolución final, y aunque podríamos suponer que, argumentativamente, Las Casas fue vencedor, en la práctica de la Conquista y de todas las consecuencias de esta, lo que se impuso fue el pensamiento irracional de Sepúlveda. Aunque para la época este pareció ser racional y coherente (cuestión que se ha perpetuado en la actualidad).

¿Eran libres los habitantes del Nuevo Mundo? ¿Podría ser conquistado ese territorio? ¿Cuál era la legalidad que para ello? ¿Debían ser evangelizados? ¿De qué manera? ¿Era válido hacerlo por la fuerza?

Si analizamos esto desde una perspectiva antropológico-filosófica, se advierte que lo que estaba en tela de juicio era la dignidad humana de los habitantes del Nuevo Mundo. Cuál era la condición de humanidad que revestían para definir cómo tratarlos y evangelizarlos, fue el eje final de la discusión.

Si bien había una bula de 1537 (Sublimis Deus) que presuponía la racionalidad de los indios, pues estos eran humanos y tenían, en consecuencia, derecho a la libertad y la propiedad, así como derecho a abrazar el cristianismo -que debía serles predicado pacíficamente- la Disputa siguió cuestionando el nivel de humanidad y el modo de evangelizarlos, en función de las posibilidades de compresión que les predicaban. Esta instancia, es la que en términos de Apel, Dussel refiere como cómo incorporar al otro en la comunidad de comunicación.

\section{¿Cómo concebir al Otro? Tensiones entre la ética del discurso y la ética de la liberación.}

La conferencia 5 titulada Crítica del 'mito de la Modernidad' tiene como interlocutor a K-O. Apel (1922-2017) y su ética del discurso. Desde el análisis de la controversia de Valladolid, se ejemplifican los modos en los que el discurso moderno incluye al Otro en la comunidad de comunicación por medio de la razón emancipadora. En La ética de la liberación ante la ética del discurso (1996) Dussel responde al trabajo de Apel: La ética del Discurso ante el desafío de la Filosofía Latinoamericana de la Liberación (1995). Allí afirma que "«re-conocer» a alguien en la asimetría como persona, igual, y como Otro, es ya la «experiencia ética» (el factum) que lo descubre como dominado o excluido desde su previo conocimiento como persona" (DUSSEL, 1993, p.138). 
El debate entre Apel y Dussel se inició en 1989 en Friburgo, Alemania, en un Seminario Internacional con el objetivo explícito de abrir un diálogo entre dos modelos de fundamentación de la ética. En el prólogo del libro que recopila la historia de estos debates -pues fueron varios a lo largo de los años- Fornet Betancourt afirma que:

\begin{abstract}
el debate entre la ética del discurso y la ética de la liberación constituyó el eje central de las primeras etapas recogidas por esta iniciativa en favor de un equilibrio comunicativo en las relaciones filosóficas entre los países del Norte y del Sur, tan marcadas todavía por el desequilibrio epistemológico y la consecuente asimetría reinante en la organización y/o institucionalización de los estudios filosóficos (APEL-DUSSEL, 2004, p.9).
\end{abstract}

Coetáneamente, alrededor de 1970, Apel iniciaba su Ética Discursiva en Alemania, mientras que Dussel desarrollaba la Ética de la Liberación en Argentina. En la introducción al libro que tienen en conjunto, se señala que Dussel pretende responder a los mismos procesos planetarios que Apel define como la expansión de la ciencia y de la técnica, pero la diferencia es que Dussel lo aborda desde un punto de vista político y económico. ${ }^{3}$

Disentimos aquí, ya que no se trata sólo de diferentes formas de abordar los mismos problemas, sino sobre todo, de puntos de partida distintos. Apel toma como principio básico de su ética, la solución racional entre intereses y pretensiones en un conflicto. Esto significa que si se cumplen las reglas de una correcta argumentación y se logra una comunidad real de comunicación en la que participen, en condición de igualdad, todos los afectados, es solo la fuerza de los argumentos la que puede dirimir el conflicto. Según W. Kuhlmann, la constelación básica es "el conflicto de intereses y pretensiones entre sujetos de razón de aproximadamente la misma fuerza y competencia y de derechos iguales" (APEL-DUSSEL, 2004, p.14).

Claro que el problema que va a señalar Dussel, en función de su lugar de enunciación, es que no todos tienen la misma fuerza, ni competencia, ni derechos iguales. De hecho, tanto en la Disputa deValladolid como en sus actualizaciones contemporáneas, se entrama un discurso que ejerce un determinado poder sobre el otro hasta el punto de implicar la quita de derechos a otros sujetos e incluso, la eliminación de esos otros por el hecho de no asumir el discurso hegemónico. Así, cuando una supuesta argumentación anula al otro en su identidad y en su vida, ya no hay argumentación racional posible.

Dussel sostiene que el Otro, excluido de la comunidad de comunicación, no es excluido sin más, sino que es víctima del sistema capitalista imperante, que inicia con la Conquista de América. La Filosofía de la Liberación -y la ética consecuente- hace una clara opción por los pobres y oprimidos de la periferia luchando por su liberación. Ese es el eje de su reflexión filosófica.

3 Hay mucha bibliografía respecto a este debate. Recomendamos remitir al prólogo y la introducción del libro que compila el debate APEL-DUSSEL 2004. 
Su Ética de la Liberación presenta 3 elementos: a) una metafísica de la alteridad (el otro como heterogeneidad y distinción), b) una teoría del conocimiento (comprender la exterioridad del otro implica la experiencia de la proximidad y el encuentro) y c) una teoría de la praxis de liberación (el grito del oprimido exige justicia). El paradigma de una auténtica liberación es el éxodo de los oprimidos; cuyas instancias centrales son:

I) el punto de partida es la dominación como negación de la exterioridad constitutiva e histórica del otro, la instrumentalización de su rostro; la dominación es la negación de la relación «cara a cara»; la totalización del Yo o del Nosotros;

2) el Éxodo como la ruptura del sistema de dominación; el proceso de autoencuentro; esto significa la separación del poder introyectado y la afirmación y reconstrucción de la propia identidad;

3) la construcción de un nuevo orden en donde el oprimido pueda vivir como una persona original y diferente en igualdad con los otros. (APEL-DUSSEL, 2004, p.15).

Frente a la Ética del Discurso, que comprende la pobreza como una evidencia de exigencia ética, Dussel denuncia la instancia ideológica de la imperante validación científica -que pone a unos por encima de otros- y señala que la posibilidad de argumentar dentro de una comunidad de comunicación supone previamente el acto de ser reconocido en su alteridad como participante. Pero dicho acto es por el contrario, "pre-cientítico, pre-reflexivo" porque responde a una ética, en términos levinasianos, originaria, "anterior a toda argumentación" (DUSSEL. 1993, p.138). Ya que, "si se argumenta, es porque el otro es persona -y no a la inversa-" (DUSSEL. 1993, p.139). La crítica a la instancia de la validación científica supone que el reconocimiento del Otro como Otro es un acto previo a la argumentación, que posibilita la crítica a la totalidad del sistema vigente, que niega la alteridad.

Dussel comprende la cuestión de la alteridad desde la crítica a la concepción ontológica de totalidad, tal como se ha desarrollado en la metafísica occidental desde Platón a Hegel. La alteridad del Otro supone dos dimensiones "como dominado en el sistema o totalidad (subsunción) y como exterioridad en tanto excluido por el mismo sistema" (DUSSEL, 1993, p.142). La relación con la razón distinta del Otro inicia un proceso de apertura del mundo propio hacia la trascendencia del Otro. Ante la comunidad ideal de comunicación y su pretensión de simetría y sincronía, Dussel señala en la exterioridad del sistema, la alteridad del Otro y la asimetría y diacronía reales. Su distinción entre objetividad y realidad como alteridad pone en cuestión las mediaciones desde las que la razón occidental subsume la alteridad en la totalidad, es decir la encubre.

Dussel introduce su crítica al mito de la modernidad en los '90, retomando la discusión con Apel, y opone resistencia a las corrientes posmodernas. En el contexto del Humanismo Renacentista se convoca a reconocidos humanistas para reflexionar respecto 
del problema jurídico que acontece con la colonización de América. Dussel analiza tres posiciones respecto de cómo se incluye al Otro en la comunidad de comunicación ante el modo de vida auto-denominado por los conquistadores como civilización.

\section{La construcción y la crítica al "mito de la Modernidad".}

Dussel retoma la Disputa de Valladolid de manera explícita, con el fin de pensar tres modos de conceptualización del otro, es decir del habitante de llamado Nuevo Mundo. Las tres perspectivas que retoma el filósofo mendocino implican, no sólo la manera de considerar al otro, sino también tres modos de concebir la modernidad.

La primera es la representada por Ginés de Sepúlveda. Dussel sostiene que esta perspectiva asume la modernidad como emancipación, pues

se determina a la otra cultura como inferior, ruda, bárbara, siendo sujeto de una
culpable "inmadurez". De manera que la dominación (guerra, violencia) que
se ejerce sobre el Otro es, en realidad, emancipación, "utilidad", "bien", del
bárbaro que se civiliza, que se desarrolla o "moderniza" (DUSSEL, 1994, p. 70).

La argumentación de Sepúlveda resulta impactante por su sinceridad. Afirma que las obras arquitectónicas que deslumbraron a los colonizadores no es razón para considerar a estos pueblos como civilizados. Lo afirma duramente en una de sus argumentaciones: "el tener casas y algún modo racional y alguna especie de comercio, es cosa a que la misma necesidad natural induce, y sólo sirve para probar que no son osos, ni monos y que no carecen totalmente de razón" (DUSSEL, 1994, p. 71).

Sostiene Sepúlveda que son seres racionales y en este sentido humanos. No se discute, como frecuentemente se cree, la humanidad de los indios, pero sí la clase o tipo de humanidad que estos revisten. Vale destacar aquí que el mismo Ginés afirma que "no carecen totalmente de razón", el tema estaría en el tipo o grado de racionalidad, pues afirma más adelante en su texto, que son serviles a reyes y que no hacen uso de su libre voluntad. Tampoco poseen propiedad privada, por lo que no pueden disponer de sus campos, ni tienen capacidad de heredar. Tanto la libertad como la propiedad son íconos de la modernidad europea, de tinte liberal y por ello las críticas apuntan en esos flancos.

Contemporáneamente, ambas nociones han sido cuestionadas pues se constituyen de manera paradójica, tanto en el individuo en sí mismo, como en su relación con los demás. Instancias que consideramos de hecho inseparables, pues no hay constitución de ningún sujeto -ni aun del individuo moderno- que pueda realizarse sin otro. La alteridad nos constituye de manera intrínseca y esto es un principio fundamental, también en la obra de Dussel, a partir de sus lecturas de Levinas. El otro nos constituye y a la vez nos excede, para seguir siendo otro y no quedar atrapado en lo mismo; es la tensión de la que da cuenta la obra icónica del filósofo de la alteridad, titulada de manera explícita, Totalidad e Infinito (LEVINAS, 1977). 
En relación con la constitución individual del individuo moderno, la perspectiva biopolítica cuestiona estas atribuciones, que fueron pensadas como derechos inalienables del individuo. Estos derechos naturales se constituyen, originariamente, para proteger al individuo pero, paradójicamente, son los mismos que impiden su desarrollo, como analizan en varios de sus textos, tanto Agamben (1998) como Espósito. (2006, 2012). En lo que respecta a la constitución del individuo en relación con los demás, consideramos que siempre estas atribuciones -igualdad, libertad y propiedad- se han dado de manera relacional, aunque se hayan constituido como supuestos derechos naturales que todos los seres humanos poseían por el mero hecho de serlo. Esta igualdad de derechos no ha sido de manera universal ni absoluta, sino justamente, de manera comparativa y jerarquizada; pues se es libre en tanto hay otros que no lo son y se es propietario porque hay desposeídos o porque se desposee a los demás. Esto sucede también con la Conquista de América y se pone de manifiesto en la Disputa que analizamos, pero a su vez sigue sucediendo en la actualidad. Todo lo que se inicia en la Conquista sigue vigente, con matices, pero vigente al fin. Motivo por el que Dussel retoma la Disputa, pues como señala "este discurso tal como se desarrolló en el tiempo del nacimiento de la Modernidad, en la disputa de Valladolid en 1550, (es) la más insigne de los últimos quinientos años, por sus consecuencias y actual vigencia" (DUSSEL, 1994, p. 70).

Así como la biopolítica italiana retoma la paradoja de los derechos naturales en la constitución de individuo moderno, un exponente como Aníbal Quijano (1928-2018) denuncia la colonialidad del poder como una trama que se inicia con la Conquista de América, cuya consecuencia sigue vigente en la actualidad. La perspectiva de la colonialidad denuncia la trama relacional de la modernidad y afirma que la colonialidad es la cara oculta de la modernidad. Se da de manera conjunta como modernidadcolonialidad ${ }^{4}$. Quijano sostiene como instancia central la idea de raza, que si bien no se manifiesta de manera explícita en la Disputa, es parte del sustrato que se mantiene presente en su ausencia; pues bajo la excusa de cómo evangelizar a los pueblos originarios o en palabras de Apel cómo incorporar al otro en la comunidad de comunicación, lo que se discute es la jerarquía humana de los habitantes originarios, cuestión que no mucho tiempo después se entramará y clasificará bajo el invento de la raza, vigente hasta la actualidad.

La raza es uno de los ejes fundamentales del patrón de poder colonial, perpetuado hasta hoy. En palabras de Quijano:

La globalización en curso es, en primer término, la culminación de un proceso que comenzó con la constitución de América y la del capitalismo colonial/ moderno y eurocentrado como un nuevo patrón de poder mundial. Uno de los ejes fundamentales de ese patrón de poder es la clasificación social de la población mundial sobre la idea de raza, una construcción mental que expresa

4 Es vasta la bibliografía sobre Modernidad-Colonialidad. Artículos que recogen su historia y problemáticas son: GRAMAGLIA, 2018; QUINTERO y PETZ, 2009. 
la experiencia básica de la dominación colonial y que desde entonces permea las dimensiones más importantes del poder mundial, incluyendo su racionalidad específica, el eurocentrismo. Dicho eje tiene, pues, origen y carácter colonial, pero ha probado ser más duradero y estable que el colonialismo en cuya matriz fue establecido. Implica, en consecuencia, un elemento de colonialidad en el patrón de poder hoy mundialmente hegemónico. (QUIJANO, 2000, p.1)

El sociólogo peruano diferencia colonialismo y colonialidad y para ello nos remite a su artículo Colonialidad y modernidad/racionalidad, publicado en la revista Perú Indígena. Allí describe su concepción de modernidad-colonialidad, pero debe primero definir qué es la colonialidad. El colonialismo en América Latina concluye, de manera más o menos generalizada a fines del siglo XIX (aunque aún hay enclaves coloniales). No obstante, sostiene Quijano, que hay instancias del colonialismo que se perpetúan, más allá del fin de este. La subjetividad que se crea bajo la trama del colonialismo, las relaciones intersubjetivas, la opresión, la organización de la vida, del trabajo, la concepción de la organización y la centralidad del mundo en función de Europa, entre otras, permiten que Quijano sostenga el concepto de colonialidad como la estructura de poder que se perpetua más allá del fin del colonialismo. Este patrón de poder se sostiene sobre dos ejes, uno es la raza como factor de clasificación social y otro es el control del trabajo bajo la estructura del capital, cuestión que deviene en el capitalismo.

Cuando ambos ejes se entrecruzan, termina de conformarse este patrón de poder colonial, ya que se produce una clasificación racial del trabajo y de todas las instancias que devienen de él. Esta trama, afirma Quijano, proviene del colonialismo, se crea allí, pero lo excede por mucho, por lo que es necesario generar otro concepto que posibilite pensar la presencia del colonialismo en la actualidad. La idea de raza ha sido la más duradera y estable matriz colonial y pretende historizar su constitución de este modo:

... la estructura colonial de poder produjo las discriminaciones sociales que posteriormente fueron codificadas como "raciales", étnicas, "antropológicas" o "nacionales", según los momentos, los agentes y las poblaciones implicadas. Esas construcciones intersubjetivas, producto de la dominación colonial por parte de los europeos, fueron inclusive asumidas como categorías (de pretensión "científica" y "objetiva") de significación ahistórica, es decir como fenómenos naturales y no de la historia del poder. Dicha estructura de poder, fue y todavía es el marco dentro del cual operan las otras relaciones sociales, de tipo clasista o estamental. En efecto, si se observan las líneas principales de la explotación y de la dominación social a escala global, las líneas matrices del poder mundial actual, su distribución de recursos y de trabajo entre la población del mundo, es imposible no ver que la vasta mayoría de los explotados, de los dominados, de los discriminados, son exactamente los miembros de las "razas", de las "etnias", o de las "naciones" en que fueron categorizadas las poblaciones colonizadas, en el proceso de formación de ese poder mundial, desde la conquista de América en adelante. (QUIJANO, 1992, p. 12). 
La historización de la codificación racial que realiza Quijano, permite comprender una postura como la de Sepúlveda y las reverberancias actuales de su planteo. Esta pretensión científica y objetiva de considerar a una raza o nación como superior la europea, claro está-, es el núcleo de la argumentación de Sepúlveda y la justificación para ejercer la violencia sobre aquellos considerados inferiores. Otra de las claves para entender el proceso de construcción de lo que Dussel denomina mito de la modernidad es la constitución de esta superioridad como ahistórica. Así se sostiene la superioridad de algunos como natural y la inferioridad de otros del mismo modo. Se descontextualiza esta construcción, lo que produce una percepción de la desigualdad como ínsita a la naturaleza humana. por lo que esta se perpetúa de suyo; mismo argumento que en la actualidad.

La superioridad natural es lo que lleva a Sepúlveda a considerar no solo justa, sino necesaria la conquista y evangelización de los pueblos. Se trataría de una obligación, de los pueblos superiores para con los inferiores, por ello Dussel sostiene que la concepción de modernidad que caracteriza la postura de Sepúlveda es la de la modernidad como emancipación. De hecho, sostiene Ginés que como los pueblos originarios son bárbaros y no aceptan la civilización europea, se ven obligados a utilizar la violencia para cumplir su mandato civilizatorio. Traemos aquí las duras palabras de Sepúlveda en su texto De la justa causa de la guerra contra los indios, con las que Dussel inicia su 5ta Conferencia:

La primera [razón de la justicia de esta guerra y conquista] es que siendo por naturaleza siervos los hombres bárbaros [indios], incultos e inhumanos, se niegan a admitir el imperio de los que son más prudentes, poderosos y perfectos que ellos; imperio que les traería grandísimas utilidades, magnas commoditates, siendo además cosa justa por derecho natural que la materia obedezca a la forma, el cuerpo al alma, el apetito a la razón, los brutos al hombre, la mujer al marido, lo imperfecto a lo perfecto, lo peor a lo mejor, para bien de todos (utrisque bene) (DUSSEL, 1994, p. 69).

Se ve claramente como el derecho natural funciona solo para algunos, pues mientras aquí implica obediencia y sumisión, para otros implica igualdad, libertad y propiedad, cuestión que nos hace cuestionar lo natural del derecho.

Es importante considerar en esta modernidad como emancipación la adjudicación de la culpabilidad a los conquistados, ya que deberían haber aceptado complacientes la Conquista. Al negarse, los civilizadores se ven obligados a utilizar la fuerza y hacer la guerra, no por voluntad de ellos, sino por la negación de los indios. Con el discurso de Sepúlveda se construye entonces lo que Dussel Ilama mito de la modernidad, que implica la identificación de la modernidad como proyecto y proceso emancipatorio y liberador, invisibilizando a la vez el ejercicio de violencia, fuerza y dominación. Se trata de la construcción hegemónica de un concepto de modernidad que implica ideas tales como razón, progreso, desarrollo, ciencia, libertad, igualdad, ilustración, que son con las que 
usualmente se asocia a la modernidad, en contraposición también a la oscuridad y opresión medieval. ${ }^{5}$ Dussel denuncia que la concepción de modernidad como emancipación no se hace cargo de la violencia que ejerce, o la asume como el costo necesario de la civilización. El pensador latinoamericano retoma los corolarios con los que Sepúlveda sostiene su argumentación. Presentamos los más elocuentes:

$1^{\circ}$ : la dominación que Europa ejerce sobre otras culturas es una acción pedagógica o una violencia necesaria (guerra justa), y queda justificada por ser una obra civilizadora o modernizadora; también quedan justificados eventuales sufrimientos que puedan padecer los miembros de otras culturas, ya que son costos necesarios del proceso civilizador, y pago de una "inmadurez culpable". $2^{\circ}$ : el conquistador o el europeo no sólo es inocente, sino meritorio, cuando ejerce dicha acción pedagógica o violencia necesaria. $3^{\circ}$ : las víctimas conquistadas son "culpables" también de su propia conquista, de la violencia que se ejerce sobre ellas, de su victimación, ya que pudieron y debieron "salir" dé la barbarie voluntariamente sin obligar o exigir el uso de la fuerza por parte de los conquistadores o victimarios; es por ello que dichos pueblos subdesarrollados se tornan doblemente culpables e irracionales cuando se rebela contra esa acción emancipadora-conquistadora (DUSSEL, 1994, p. 73).

Aquí queda articulado el mito, donde se justifica la violencia como costo necesario. Dussel sostiene que este mito es una gigantesca inversión porque los conquistadores violentos se erigen como emancipadores y civilizadores inocentes y meritorios, y los conquistados $-y$ violentados- son vistos como culpables, por no salir voluntariamente de aquello que los europeos consideraron como bárbaro, salvaje e irracional. Considera que, "Ginés de Sepúlveda termina por caer en el irracionalismo, como toda la Modernidad posterior, por la justificación del uso de la violencia en lugar de la argumentación para la inclusión del Otro en la "Comunidad de comunicación"" (DUSSEL, 1994, p. 74). Una vez que el Otro ingresó en la comunidad de comunicación se pregona la racionalidad comunicativa, pero el ingreso a esta es por la fuerza.

Sepúlveda retoma una interpretación de Agustín de Hipona, de una parábola del Nuevo Testamento, en la que el señor llama a todos a su casa, primero como una invitación y luego los compele a entrar. Ginés utiliza la misma parábola para pensar en la evangelización de los pueblos originarios y asume que hubo una primera invitación y luego hay que obligarlos a "recibir el imperio de los cristianos" (DUSSEL, 1994, p. 74).

La consideración del Otro en esta perspectiva de modernidad es, como hemos ido describiendo, la de un otro bárbaro, salvaje, casi inhumano, irracional y por ello no puede

5 Cabría revisar también si las ideas con las que asociamos al medioevo no son fruto de esta modernidad hegemónica. No porque desconozcamos la opresión eclesiástica y las jerarquías feudales, pero cabe la pregunta de si la construcción de sentido común acerca del medioevo no tiene como lugar de enunciación el proyecto científico-técnico de la modernidad con el eje puesto en el progreso y la razón; instancias por demás cuestionadas en la contemporaneidad. 
tener una palabra válida para expresar su voluntad, su decisión, su cosmovisión. Aun ya dentro de la comunidad de comunicación, en este caso, del imperio de los cristianos, no hay posibilidad de que su palabra sea escuchada, de que revista una racionalidad considerada por los dominadores como igualmente valiosa. El supuesto de una comunidad de comunicación en la que los participantes deben estar en pie de igualdad, no se cumplió en tiempos de la Conquista de América, ni tampoco hoy con los pueblos históricamente colonizados. Como sostiene Quijano, la trama de poder que se constituyó con la Conquista, fue y aun es, el marco de las relaciones sociales que oprimen bajo las categorías de raza, clase y género. Las principales líneas de explotación a nivel global, conservan la misma estructura y distribución que se inauguró hace cinco siglos.

El segundo ponente de la Disputa, no reviste gran importancia para la discusión que abordamos, por lo que haremos una breve mención. Se trata de Gerónimo de Mendieta (1525-1604), uno de los primeros misioneros franciscanos que se instaló en México. En relación con la consideración del otro y la perspectiva de modernidad que asume, Mendieta se pliega a la cosmovisión de Sepúlveda, pues considera que los aztecas habían vivido en el paganismo y la idolatría como los hebreos en Egipto, y que Hernán Cortez era el Moisés que Ilegó a liberarlos de la servidumbre. Plantea, al igual que Sepúlveda una perspectiva emancipatoria. Utiliza la misma parábola bíblica que retoma Sepúlveda, y presume también que si los pueblos originarios no acatan la invitación del señor, habrá que obligarlos y estará justificada la violencia, bajo el mismo parámetro de guerra justa.

La diferencia de Mendieta radica en lo que había que hacerse después, ya que una vez que el otro entraba en la comunidad de comunicación, se respetaban y conservaban las tradiciones aztecas que no se contrapusieran con el cristianismo, como por ejemplo, sus lenguas autóctonas, sus vestimentas, sus costumbres, sus autoridades políticas. Dussel considera que se trata de un proyecto modernizador utópico que "partía de la exterioridad (la que no había sido destruida por la conquista), para desde allí organizar una comunidad cristiana fuera del influjo hispánico" (DUSSEL, 1994, p. 76).

En 1564 culminó el paternalismo franciscano que fue fuertemente criticado por los colonos europeos, cuando por orden de Felipe II, los colonos tomaron el control de las colonias e impusieron el repartimiento como modo de explotación. Esta instancia aniquiló lo que había quedado de la exterioridad cultural del indio, y para Mendieta fue como volver a la esclavitud de Egipto, de la cual supuestamente los habían emancipado.

La última postura que retoma Dussel es la de Bartolomé de las Casas (1474-1566), quien fue primero encomendero español y luego fraile dominico. Llegó al continente americano en 1502 y se ordenó sacerdote en 1512. Se involucró intensamente con las culturas originarias e incluso renunció a su propia encomienda. Consideraba inhumano el trato de los colonos hacia los pueblos originarios, quienes iban extinguiéndose fruto de los trabajos forzados y la explotación a la que eran sometidos. 
Dussel sostiene que la postura que asume Las Casas es la de una Crítica al "mito de la modernidad", porque considera que en ella:

Asume lo mejor del sentido emancipador moderno pero descubre la irracionalidad encubierta en el "mito" de la culpabilidad del Otro. Por ello niega la validez de todo argumento en favor de la legitimación de la violencia o guerra inicial para "compeler" al Otro a formar parte de la "comunidad de comunicación (DUSSEL, 1994, p. 77).

No se trata de la argumentación racional dentro de la comunidad de comunicación, sino, como ya mencionamos, acerca de cómo se ingresa a la misma. Se trata de la condición de posibilidad de la participación racional misma.

Tanto Sepúlveda como Mendieta asumen un primer momento irracional -la guerra justa- para luego iniciar la argumentación racional. Bartolomé exige que todos los momentos sean racionales, pues no hay posibilidad de justificar de manera alguna el uso de la violencia.

La emancipación de la pretendida barbarie no puede justificar la violencia, ni tiene proporción con el nuevo tipo de dominación, pues como afirma Mendieta, si se trata de emancipar no se los puede someter nuevamente a sistemas serviles y opresivos. Esto denuncia Bartolomé, siendo el primero que defiende la capacidad racional de los pueblos originarios. En el prólogo de la Apologética historia sumaria defiende a los pueblos colonizados señalando que:

La causa final de escribirla fue conocer todas y tan infinitas naciones [...] infamadas por algunos [...] publicando que no eran gentes de buena razón para gobernarse [...] Para demostración de la verdad, que es en contrario, se traen y copilan en este libro (DUSSEL, 1994, p. 78).

Las argumentaciones desarrolladas por los otros dos ponentes, sobre todo por Sepúlveda, caracterizan burdamente a los pueblos originarios y aluden a la dicotomía civilización-barbarie, racionalidad-irracionalidad, cristianismo-paganismo, entre otros que funcionan estructuralmente en la constitución de la subjetividad moderna. ${ }^{6}$ Es Bartolomé el primero que señala que no es lícita esta dualidad y menos como justificación de la guerra. En función de ello escribe su Apologética, para señalar que los pueblos originarios tenían cultura, formas comunitarias de organización, desarrollos arquitectónicos, astronómicos, religiosos, etc. por lo que sostiene que habría que evangelizarlos sin negar su realidad, sino incorporándola al proceso. Dussel, apelando a su terminología levinasiana, afirma que no hay que negar la alteridad. "Hay que asumir la modernidad sin legitimar su mito" (DUSSEL,1994, p.79). Esto se logra para Bartolomé por medio de la argumentación

6 Para ampliar la dualidad categorial que ha trascendido largamente a América Cfr. ROIG, 2011. Particularmente el capítulo 1 Entre la civilización y la barbarie y Civilización y barbarie. Algunas consideraciones para su tratamiento filosófico. 
racional, único modo de convencer a los pueblos originarios que el cristianismo era la verdadera religión y, agrega Dussel que hay que complementarlo con una vida coherente, si no se caería en una contradicción performativa, como sucede en toda la Conquista de América. Esta contradicción es parte de lo que critica Bartolomé, por lo que Dussel sostiene la necesidad de una gran inversión, la de los roles de víctima y victimario en el escenario constitutivo de la Modernidad. En palabras de Bartolomé: "Por todos los textos citados se ve que los que mandan son los principales culpables en cuanto a la gravedad de los crímenes y de los daños que se hacen en la guerra contra los infieles, pecando más gravemente que los demás" (DUSSEL, 1994, p. 81).

Los pecados que les endosan a los Ilamados infieles no se comparan, a ojos de Bartolomé, con la barbarie ejercida por los supuestos civilizadores. De allí que Dussel sostenga que, es Bartolomé quien adquiere el máximo de conciencia crítica posible, pues se coloca en el lugar de los oprimidos y pone así en cuestión las premisas civilizadoras de la Modernidad. Afirma conclusivamente que:

Que esta guerra sea injusta se demuestra, en primer lugar teniendo en cuenta [...] que la merezca el pueblo contra el cual se mueve la guerra, por alguna injuria que le haya hecho al pueblo que ataca. Pero el pueblo infiel que vive en su patria separada de los confines de los cristianos [...] no le ha hecho al pueblo cristiano ninguna injuria por la que merezca ser atacado con la guerra. Luego esa guerra es injusta (DUSSEL, 1994, p. 81).

No hay más que pueda explicitar el fraile, defensor de los pueblos originarios. No obstante, su racionalidad crítica, aunque por demás argumentada, no venció en la praxis. De hecho Dussel sostiene que:

la razón crítica de Bartolomé fue sepultada por la razón estratégica, por el realismo cínico de Felipe II -y de toda la Modernidad posterior, que llegó al sentido crítico „ilustrado" (Aufgeklärt) intraeuropeo, pero que aplicó fuera de sus estrechas fronteras una praxis irracional y violenta... hasta hoy, a finales del siglo XX (DUSSEL, 1994, p. 81).

Así se erige el mito de la Modernidad, como instancia civilizadora, pero con una violencia como mecanismo necesario que servirá para combatir a los infieles y propagar el cristianismo en el siglo XVI, para irradiar el progreso con la consolidación de la Modernidad, para extender los derechos con la democracia contemporánea y en la actualidad, en función del libre mercado, la globalización y la libertad. Instancias que perpetúan la misma estructura civilizatoria moderna, que clasifica a los sujetos en el binomio de civilización-barbarie, aunque más aggiornado, pero que los sigue ubicando en tanto víctimas inocentes de ejercer la violencia y victimarios por resistirse a la civilización occidental y cristiana, y agregamos blanca, masculina y heterosexual. 
Destacamos el pensamiento humanista de vanguardia de Bartolomé de las Casas, único defensor de la dignidad humana en la época; aunque no podemos obviar su paternalismo cristiano y su postura evangelizadora. Aunque contrafácticamente, consideramos que la evangelización y la conquista de América no fue más que expoliación y avasallamiento, instancias que Dussel conceptualiza como el encubrimiento del otro. Este encubrimiento se ha perpetuado, negando cualquier alteridad que no cuadre en la hegemonía establecida. Su reactualización, tal como mencionamos más arriba, no había sido explícitamente en términos evangelizadores -sino desde el progreso, la globalización, etc- sin embargo la misión evangelizadora vuelve a estar en el centro de la escena, con la misma estructura que hace 500 años. Vuelve una diferenciación en torno a lo humano, segmentando el acceso a derechos. Se reactualiza un discurso conservador de la verdad y el bien que intenta civilizar -violentamente- a aquellos que se corren de lo establecido o que no entran voluntariamente en ese camino, por lo que además de violentarlos, una vez más, los culpabilizan. ¿Será momento de invertir, de una vez y para siempre, el mito de la modernidad y asumir las alteridades avalando la dignidad humana de todos y cada uno en la práctica cotidiana? Ojalá podamos.

Federica Scherbosky és profesora de Filosofía (Universidad Nacional de Cuyo, 2008) y doctora en Filosofía (Universidad de Buenos Aires, 2014). Es investigadora asistente de CONICET, en el Instituto de Ciencias Humanas, Sociales y Ambientales, CCT-Mendoza. Participa en Proyectos de Investigación en Filosofía Práctica e Historia de las Ideas. Docente investigadora en la Facultad de Educación de la UNCuyo, cátedra de Antropología Filosófica. Actualmente se desempeña como Directora de Posgrado en la misma facultad. También es docente en la cátedra de Pensamiento y arte latinoamericano de la Facultad de Artes y Diseño de la UNCuyo. Ha publicado artículos en revistas especializadas y capítulos de libro, acerca de filosofía intercultural, teorías del reconocimiento, problemática de la cultura y la alteridad, entre otros. Su tema de trabajo actual es el Movimiento Antropofágico Brasilero, específicamente las categorías de subjetividad, racionalidad y conflicto, en relación con las teorías del reconocimiento y los planteos de la diversidad.

fedescherbo@yahoo.com.ar 


\section{Referencias}

AGAMBEN, G. Homo Sacer. Valencia: Pre-textos. 1998.

APEL, K-O Y; DUSSEL, E. Ética del discurso y ética de la liberación. Madrid: Trotta, 2004.

DUSSEL, E. La ética del discurso ante la ética de la liberación. En XIX Congreso Mundial de Filosofía. 1993. Disponible en línea: http://isegoria.revistas.csic.es/index.php/isegoria/article/view/229/229

DUSSEL, E. 1492. El encubrimiento del otro. Hacia el origen del mito de la Modernidad. La Paz: UMSA. [1992]-1994. Disponible en línea: http://biblioteca.clacso.edu.ar/clacso/otros/20111218114130/1942. pdf

DUSSEL, E. Europa, modernidad y eurocentrismo. En: La colonialidad del saber: eurocentrismo y ciencias sociales. Perspectivas latinoamericanas. Buenos Aires. CLACSO. 2000. Disponible en: http:// bibliotecavirtual.clacso.org.ar/clacso/sur-sur/20100708040738/4_dussel.pdf

ESPÓSITO, R. Communitas: origen y destino de la comunidad. Buenos Aires: Amorrortu. 2012.

ESPÓSITO, R. Bios. Buenos Aires: Amorrortu. 2006.

GRAMAGLIA, P. El proyecto Modernidad/Colonialidad.Aportes para la construcción de un conocimiento autónomo de América Latina. En: Pelícano. Vol 4. Universidad Católica de Córdoba, 2018. Disponible en: http://revistas.bibdigital.uccor.edu.ar/index.php/pelicano/article/view/1426

LEVINAS, E. Totalidad infinito. Salamanca: Sígueme [1977] 2012.

QUIJANO, A. Colonialidad del poder, eurocentrismo y América Latina, en Lander, Edgardo (comp.) La colonialidad del saber: eurocentrismo y ciencias sociales. Perspectivas latinoamericanas Buenos Aires: CLACSO. 2000. p. 246.

QUIJANO, A. Colonialidad y modernidad/racionalidad. En: Perú Indígena. 13(29): 11-20, Lima. 1992

QUINTERO, P y PETZ, I. Refractando la modernidad desde la colonialidad. Sobre la configuración de un locus epistémico desde la geopolítica del conocimiento y la diferencia colonial. En: Gazeta de Antropología, 25 (2), Universidad de Granada, 2009. Disponible en: http://www.ugr.es/ pwlac/ G25_52Pablo_Quintero-Ivanna_Petz.html

ROIG, A. Rostro y filosofía en Nuestra América. Buenos Aires: Una ventana. 2011. 